\title{
A LAMP FOR OPHTHALMIC WORK
}

BY

\section{T. R. Aynsley}

CHESTERFIELD

THIs lamp will be found useful to oculists who have to work in schools, or see patients in rooms which are not fully fitted up for ophthalmic work. An ordinary living room or consulting room can quickly be adapted in this way.

The apparatus is simply a combination of the Tudor Thomas Screen (Messrs. Dixey and Son) and an "Adjusto-lite" (widely advertised for domestic purposes and sold by most electricians). There is a diaphragm in the Thomas Screen which can be altered to suit the varying requirements of refractionists. The room is quite dark except for a smäll amount of light which passes the

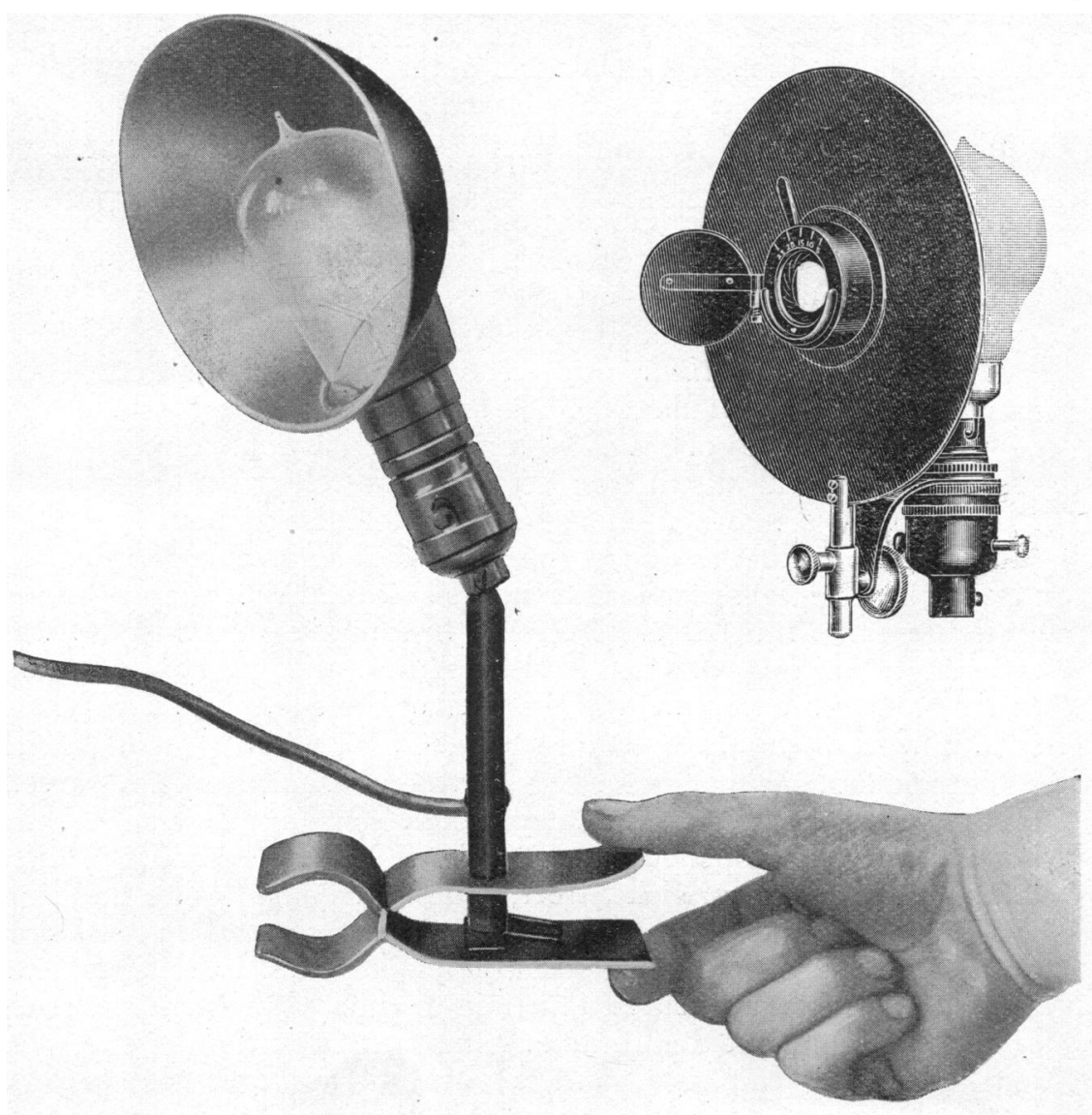


edge of the screen and is just sufficient to enable one to see the lens case and write notes. The screen can readily be swung to one side for oblique illumination of the eye, or to illuminate the test type; though personally I prefer to keep the patient sitting where the retinoscopy is done, and I have another Adjusto-lite clipped at the opposite side of the room beside the test card.

The Adjusto-lite has eight feet of flex and its base incorporates a strong felt-lined clip so that it can readily be fastened in any position and to most articles of furniture. The cost of the Adjustolite and Thomas Screen is two guineas and the whole outfit can be carried in the Adjusto-lite box in an attaché case.

\section{ANNOTATIONS}

\section{Rebuilding of the Royal Westminster Ophthalmic Hospital}

An important addition to the facilities for the study and practice of ophthalmology in London will be provided by the removal of the Royal Westminster Ophthalmic Hospital to a new and larger building in Broad Street, W.C.2, near the junction of Tottenham Court Road and New Oxford Street.

This hospital was founded in the year 1816 by Mr. G. J. Guthrie (v. Brit. Jl. of Ophthal., Vol. III, p. 145, 1919) under the patronage of the Duke of York and with the active support of the first Duke of Wellington, under whom Guthrie had served with great distinction as an Army Surgeon during the Peninsular War. An immense amount of disablement had been caused among the troops serving in the Napoleonic Wars by disorders of the eyes, especially by the so-called Egyptian ophthalmia. One of Guthrie's chief objects in founding the hospital was to enable medical officers of the Army and Navy to obtain instruction in the treatment of diseases of the eye, and he admitted such officers without fee to his courses of lectures.

Guthrie first saw patients at his private house in Berkeley Street, on the site of the present Berkeley Hotel. On January 1, 1817, the hospital was first opened in Marylebone Street, Piccadilly; later it was moved to Warwick Street, Golden Square. The building in King William Street, West Strand, was opened in 1832 and there the hospital remained for ninety-six years. Enlargements and alterations were made from time to time to provide increased accommodation, but the limits of extension upon the old site were reached some years ago, and removal to a larger site became 